\title{
Erratum to: Effect of mushroom (Schizophyllum spp.) derived $\beta$-glucan on low-fiber diet induced gut dysbiosis
}

\author{
Karthika Muthuramalingam ${ }^{1} \cdot$ Vineet $\mathrm{Singh}^{2} \cdot \mathrm{Changmin}^{\mathrm{Choi}}{ }^{1} \cdot \mathrm{Seung}_{\mathrm{In}} \mathrm{Choi}^{3}$. \\ Sanggyu Park ${ }^{4}$ Young Mee Kim ${ }^{1}$ - Tatsuya Unno ${ }^{2,5} \cdot$ Moonjae Cho ${ }^{1,6}$ (iD
}

Received: 22 May 2019 / Accepted: 7 June 2019 / Published Online: 30 June 2019

(C) The Korean Society for Applied Biological Chemistry 2019

Erratum to: J Appl Biol Chem (2019) 62(2), 211-217

https://doi.org/10.3839/jabc.2019.029

The company that provide beta glucan ask to specify the name of mushroom to Schizophyllum commune.

p. 211

Effect of mushroom (Schizophyllum commune) derived $\beta$-glucan on low-fiber diet induced gut dysbiosis

Moonjae Cho $(\triangle)$

E-mail: moonjcho@jejunu.ac.kr

Tatsuya Unno $(\bowtie)$

E-mail: tatsu@jejunu.ac.kr

${ }^{1}$ Department of Biochemistry, School of Medicine, Jeju National University, Jeju 63241, Republic of Korea

${ }^{2}$ Faculty of Biotechnology, College of Applied Life Sciences, SARI, Jeju National University, Jeju 63243, Republic of Korea

${ }^{3}$ Department of Pharmaceutical Research Institute, Quegen Biotech Co. Ltd., Seoul 429931, Republic of Korea

${ }^{4}$ Division of Life \& Environmental Science, Daegu University, Daegu 712714, Republic of Korea

${ }^{5}$ Subtropical/Tropical Organism Gene Bank, Jeju National University, Jeju 63243, Republic of Korea

${ }^{6}$ Department of Biochemistry, School of Medicine, Institute of Medical Sciences, Jeju National University, Jeju 63241, Republic of Korea

This is an Open Access article distributed under the terms of the Creative Commons Attribution Non-Commercial License (http://creativecommons. org/licenses/by-nc/3.0/) which permits unrestricted non-commercial use, distribution, and reproduction in any medium, provided the original work is properly cited. p. 212

\section{Experimental design}

The experimental scheme was given in Scheme 1. Four experimental groups with $n=11$ mice per group was classified as: normal diet group (ND), low fiber diet group-AIN 76A (LFD), LFD with $3 \mathrm{~g} /$ $\mathrm{kg}$ of $\beta$-glucan (LFD+BG1) and LFD with $5 \mathrm{~g} / \mathrm{kg}$ of $\beta$-glucan (LFD+BG2). $\beta$-Glucan ( $\beta-1,6 / 1,3$ glucan isolated from Schizophyllum commune. with average molecular weight of $1.78 \sim 1.79 \times 10^{6} \mathrm{Da}$ ) was provided by Quegen Biotech Co. Ltd., Republic of Korea. 